\title{
Nintedanib: A Novel Therapeutic Approach for Idiopathic Pulmonary Fibrosis
}

\author{
Ioannis A Dimitroulis MD PhD
}

\begin{abstract}
Idiopathic pulmonary fibrosis (IPF) is a chronic, progressive, fibrotic lung disease with no clear etiology and few therapeutic options. Growth factors that act as mediators in the development of this disease might be important therapeutic targets. Nintedanib is a triple-tyrosine kinase inhibitor and a potent antagonist of growth factors such as platelet-derived growth factor, vascular endothelial growth factor, and basic fibroblast growth factor, and it is currently evaluated in clinical trials as a potential IPF therapy. Treatment with nintedanib may slow decline in lung function, decrease the frequency of exacerbations, and improve quality of life in subjects with IPF. This observation, together with extensive safety and pharmacokinetic data from studies of nintedanib in malignancy, led the way for the clinical development of this drug in IPF. Observations from clinical trials, together with the preclinical data, suggest that nintedanib may become an important therapeutic option for individuals with IPF. High-dose nintedanib improved the quality of life, slowed the progression of lung fibrosis and the decline of lung function, and reduced the rate of exacerbations in individuals with mild and moderate IPF. This is a short review based on the available data (September 2013) on nintedanib. Key words: interstitial pneumonias; idiopathic pulmonary fibrosis; growth inhibitors; mediators; BIBF 1120; nintedanib. [Respir Care 2014;59(9):1450-1455. (C) 2014 Daedalus Enterprises]
\end{abstract}

\section{Introduction}

Idiopathic pulmonary fibrosis (IPF; also called cryptogenic fibrosing alveolitis) is a specific form of chronic, progressive, fibrosing interstitial pneumonia of unknown cause that occurs in adults and is limited to the lungs. It is associated with the histopathologic and/or radiologic pattern of usual interstitial pneumonia. In the past, treatment was aimed at minimizing inflammation and slowing the progression from inflammation to fibrosis. However, the underlying lesion in IPF may be more fibrotic than inflammatory, explaining why few subjects respond to anti-inflammatory therapies, and prognosis remains poor. ${ }^{1,2}$

The author is affiliated with the Sixth Pulmonary Department, Sotiria Hospital for Thoracic Diseases, Athens, Greece.

The author has disclosed no conflicts of interest.

Correspondence: Ioannis A Dimitroulis $\mathrm{MD} \mathrm{PhD}$, 6th Respiratory Department, "Sotiria" Hospital for Thoracic Diseases, 152 Mesogeion Avenue, Athens 11527, Greece. E-mail: idimit@ hotmail.com.

DOI: $10.4187 /$ respcare. 03023
No therapy has been proven to be efficacious, and management generally includes some combination of supportive care (eg, supplemental oxygen, pulmonary rehabilitation), consideration for participation in clinical trials introducing the use of novel drugs, consideration for lung transplant evaluation, and identification and treatment of possible comorbidities. ${ }^{1,3}$ Supportive care may be preferred as the sole treatment option for many patients given the lack of proven therapy. Prevention of gastroesophageal reflux and recurrent microaspiration may slow disease progression. A number of other agents (eg, anticoagulation, ${ }^{4}$ colchicine, ${ }^{5}$ cyclophosphamide, ${ }^{6}$ endothelin receptor antagonists, ${ }^{7}$ interferon gamma- $1 \mathrm{~b},{ }^{8}$ methotrexate, ${ }^{9}$ cyclosporine, ${ }^{10}$ penicillamine, ${ }^{11}$ imatinib, ${ }^{12}$ etanercept, ${ }^{13} \mathrm{~N}$ acetylcysteine, ${ }^{14}$ prednisone/azathioprine/ $\mathrm{N}$-acetylcysteine combination ${ }^{15,16}$ ) have been used in the past in either case series or clinical trials. The process of fibrosis is driven by innumerable growth factors and their downstream intracellular signaling pathways. It is therefore not surprising that multiple cell signaling pathways have been identified as potential therapeutic targets in IPF. ${ }^{2,17}$ When evaluated in a clinical study of subjects with IPF, imatinib given once daily at a dosage of $600 \mathrm{mg} / \mathrm{d}$ for 96 weeks demon- 
strated no significant benefit over placebo in slowing disease progression or lung function impairment. ${ }^{12}$ Imatinib, sometimes referred to by its investigational name STI-571, is a tyrosine kinase inhibitor used in the treatment of multiple cancers, most notably Philadelphia chromosome-positive $\left(\mathrm{Ph}^{+}\right)$chronic myelogenous leukemia. Like all tyrosine kinase inhibitors, imatinib works by preventing a tyrosine kinase enzyme, in this case BCR-ABL, from phosphorylating subsequent proteins and initiating the signaling cascade necessary for cancer development, thus preventing the growth of cancer cells and leading to their death by apoptosis. Because the BCR-ABL tyrosine kinase enzyme exists only in cancer cells and not in healthy cells, imatinib works as a form of targeted therapy: only cancer cells are killed through the drug's action. In this regard, imatinib was one of the first cancer therapies to show the potential for such targeted action and is often cited as a paradigm for research in cancer therapeutics. Imatinib is used to treat chronic myelogenous leukemia, gastrointestinal stromal tumors, and a number of other malignancies. One study demonstrated that imatinib mesylate was effective in patients with systemic mastocytosis, including those who had the D816V mutation in c-Kit. ${ }^{18}$ However, since imatinib binds to tyrosine kinases when they are in the inactive configuration and the $\mathrm{D} 816 \mathrm{~V}$ mutant of c-Kit is constitutively active, imatinib does not inhibit the kinase activity of the c-Kit D816V mutant. Experience has shown, however, that imatinib is much less effective in patients with this mutation, and patients with the mutation compose nearly $90 \%$ of cases of mastocytosis. ${ }^{19-21}$

Pirfenidone shows promise and is the only licensed treatment currently available for individuals with IPF.,22-25 Pirfenidone has antifibrotic and anti-inflammatory properties in various in vitro systems and animal models of fibrosis. A number of cell-based studies have shown that pirfenidone reduces fibroblast proliferation, inhibits transforming growth factor beta-stimulated collagen production, and reduces the production of fibrogenic mediators such as transforming growth factor beta. Pirfenidone has also been shown to reduce production of inflammatory mediators such as tumor necrosis factor alpha and interleukin-1beta in both cultured cells and isolated human peripheral blood mononuclear cells. These activities are consistent with the broader antifibrotic and anti-inflammatory activities observed in animal models of fibrosis. A recent Cochrane review concluded that pirfenidone appears to improve progression-free survival and, to a lesser effect, pulmonary function in patients with IPF. ${ }^{23}$ In Europe, pirfenidone is indicated for the treatment of mild-tomoderate IPF. It was approved by the European Medicines Agency in 2011. It was approved for use in Japan in October 2008 and in India in 2010.

\section{Preclinical Data}

Nintedanib (or intedanib), formally known by the development code BIBF 1120 (or BIBF-1120 or BIBF1120), is a potent, oral, small-molecule, intracellular inhibitor of the following receptor tyrosine kinases: platelet-derived growth factor (PDGF) receptors alpha and beta $\left(\mathrm{IC}_{50}=59\right.$ and $65 \mathrm{nmol} / \mathrm{L}$ ); vascular endothelial growth factor (VEGF) receptors 1,2 , and $3\left(\mathrm{IC}_{50}=13-34 \mathrm{nmol} / \mathrm{L}\right)$; and fibroblast growth factor $(\mathrm{FGF})$ receptors 1,2 , and $3\left(\mathrm{IC}_{50}=137\right.$ $108 \mathrm{nmol} / \mathrm{L}) .{ }^{26}$ Nintedanib competitively binds the ATPbinding site of its target receptor tyrosine kinase. ${ }^{27}$ The exact receptor-binding kinetics are not completely understood; however, it has been shown that nintedanib causes sustained ( $>32 \mathrm{~h}$ ) inhibition of VEGF receptor (VEGFR)-2 phosphorylation. ${ }^{26}$ At present, only limited data have been published on the effect of BIBF on fibrogenesis either in vitro or in vivo in animal models. The main published work assessing tyrosine kinase receptor inhibition in fibrosis utilized an analog of nintedanib (BIBF 1000) and found that $50 \mathrm{mg}$ of BIBF $1000 / \mathrm{kg}$, when dosed both prophylactically and therapeutically, inhibits the development of fibrosis in the rat bleomycin model. ${ }^{28}$

Although the exact role of angiogenesis in the fibrotic process is still debated, increased angiogenic activity (secondary to an imbalance in angiogenic and angiostatic factors) is seen in human fibrotic lung tissue. ${ }^{29}$ PDGF and FGF act synergistically to induce endothelial cell proliferation and contribute to pericyte recruitment and stability of blood vessel walls. ${ }^{30}$ Early administration of a VEGFR-2 inhibitor in the murine bleomycin model attenuates fibrosis, microvessel formation, and bronchoalveolar lavage inflammatory cell counts. ${ }^{31}$ In vitro, nintedanib inhibits VEGF-, PDGF-, and FGF-mediated proliferation of the 3 cell types contributing to angiogenesis: endothelial cells, vascular smooth muscle cells, and pericytes $\left(\mathrm{EC}_{50}=10\right.$ $79 \mathrm{nmol} / \mathrm{L})$.

\section{Clinical Data}

Nintedanib is an orally available 6-methoxycarbonylsubstituted indolinone (derived from indoline) (Table 1) that acts as a multiple-receptor tyrosine kinase inhibitor and that has recently shown promising results in a phase-2 trial in IPF. ${ }^{32,33}$ Originally developed as a cancer treatment, nintedanib acts by simultaneously inhibiting 3 receptor families implicated in angiogenesis: PDGF, VEGF, and FGF. ${ }^{26}$ Single angiogenic inhibitors have had limited success in clinical practice due to redundancy in angiogenic pathways. Multiple-target receptor tyrosine kinase inhibitors, including nintedanib, have been developed to address this problem. ${ }^{27}$ VEGF was found to be overexpressed by tumor cells in response to tissue hypoxemia and was reported to increase proliferation and migration of 
Table. The Identity of Nintedanib

\begin{tabular}{|c|c|c|c|c|c|c|c|}
\hline $\begin{array}{l}\text { CAS number: 656247-17-5 } \\
\text { UNII: G6HRD2P839 }\end{array}$ & Systemic Name & Trade Name & Route & Formula & $\begin{array}{l}\text { Molecular } \\
\text { Mass }\end{array}$ & Appearance & Purity \\
\hline & $\begin{array}{l}\text { Methyl (3Z)-3- } \\
\quad\{[(4-\{\text { methyl[(4- } \\
\text { methylpiperazin-1-yl) } \\
\text { acetyl]amino\}phenyl) } \\
\text { amino](phenyl)methylidene }\}- \\
\text { 2-oxo-2,3-dihydro-1H- } \\
\text { indole-6-carboxylate }\end{array}$ & $\begin{array}{l}\text { Vargatef } \\
\text { (Boehringer } \\
\text { Ingelheim) }\end{array}$ & $\begin{array}{l}\text { Oral and } \\
\text { intravenous }\end{array}$ & $\mathrm{C}_{31} \mathrm{H}_{33} \mathrm{~N}_{5} \mathrm{O}_{4}$ & $\begin{array}{c}539.6248 \\
\mathrm{~g} / \mathrm{mol}\end{array}$ & Yellow & $>99 \%$ \\
\hline
\end{tabular}

endothelial cells and to inhibit their apoptosis. ${ }^{34,35}$ PDGF is another growth factor that was found to be involved in the pathogenesis of various proliferative disorders such as tumors or pulmonary fibrosis, in which it was found to stimulate proliferation of smooth muscle cells as well as fibrogenesis. ${ }^{34,36}$ FGF was demonstrated to induce proliferation of smooth muscle cells, myofibroblasts, and fibroblasts, and its expression was found to be up-regulated in IPF. ${ }^{35}$ PDGF, VEGF, and FGF are also critical profibrotic mediators that have been shown to play a role in driving the development of fibrosis. ${ }^{28}$ The role of VEGF in IPF is contradictory. A heterogeneity of vascular remodeling in IPF has been reported, with increased vascular density in areas with low-grade fibrosis and decreased vascular density in the most extensively fibrotic lesions. ${ }^{37}$ It has been shown that there is increased expression of VEGF in capillary endothelial cells and alveolar type II epithelial cells in highly vascularized alveolar septa. In contrast, fibroblasts and leukocytes in fibrotic lesions are weakly immunoreactive with VEGF, suggesting a possible role for VEGF in the vascular heterogeneity of IPF. ${ }^{37}$ The question according to these findings is whether the increase in vascular density observed in the least fibrotic areas is actively a consequence of the development of the fibrogenic process or represents a compensatory mechanism. ${ }^{38}$ The role of VEGF in this process needs to be clarified further. Plasma VEGF concentrations do not differ between patients with IPF and controls. However, baseline plasma levels of $\mathrm{VEGF}^{39}$ are significantly related to the extent of parenchymal involvement in high-resolution computed tomography, and patients with IPF who develop progressive disease have significantly higher baseline levels of VEGF. ${ }^{39}$ In contrast, bronchoalveolar lavage fluid concentrations of VEGF are significantly depressed in patients with IPF40-42 and correlate with diffusing capacity of the lung for carbon monoxide $\left(\mathrm{D}_{\mathrm{LCO}}\right)$. The latter correlation possibly reflects the diminished epithelial surface area versus the diminished gene expression or intraluminal secretion of VEGF. ${ }^{42}$

\section{Pharmacology}

In vitro, nintedanib is rapidly metabolized by hepatocytes via ester cleavage to form the metabolite BIBF 1202.
In healthy volunteers, BIBF 1202 was detected along with the parent compound $15 \mathrm{~min}$ after nintedanib administration, with maximum concentration for BIBF 1202 being reached at $2.5 \mathrm{~h}$. The authors speculate that the rapid appearance of the metabolite results from first-pass metabolism in the intestinal wall. ${ }^{43}$ The major route of metabolite elimination is via the liver and through excretion in feces. There is minimum excretion in the urine. ${ }^{44}$ The hepatic metabolism of nintedanib is (mainly) CYP450independent. ${ }^{45,46}$ There have been no reported drug-drug interactions in clinical trials on malignancy.

\section{Safety}

Data from studies on malignancy show that the most frequent adverse events reported in the TOMORROW trial (To imprOve pulMOnaRy fibROsis With BIBF 1120) were diarrhea $(27 \%)$, nausea $(14.5 \%)$, and vomiting $(7.7 \%) .^{32}$ Serious adverse event rates were similar between groups (subjects vs controls), although the discontinuation rate due to adverse events was highest in the $150 \mathrm{mg}$ twice daily group at $30.6 \%$. This rate is in comparison to $25.9 \%$ in the placebo group and $14.0 \%$ in the $100 \mathrm{mg}$ twice daily group. The majority of the reported diarrhea cases were mild or moderate. The rate of gastrointestinal side effects rose with increasing doses of nintedanib, with $8.2 \%$ of subjects in the maximum dosing arm reporting serious diarrhea compared to 1.2 and $0 \%$ in the $50 \mathrm{mg}$ twice daily and placebo arms, respectively. Only 12 subjects (across all arms) discontinued the drug due to diarrhea.

Elevation of liver enzymes (reversible) occurred more frequently in subjects receiving $300 \mathrm{mg}$ of nintedanib/d compared to placebo. There were, however, only 9 clinically important episodes of liver enzyme elevation (3 times the upper limit of the normal range) across all of the treatment arms. Only 2 subjects needed to discontinue the drug due to hepatotoxicity, and there were no cases of druginduced liver failure. All liver function tests normalized with either reduction or discontinuation of nintedanib. Ongoing safety studies include an extension of the TOMORROW trial (ClinicalTrials.gov identifier NCT01170065) and a study, in Japanese subjects, of nintedanib given together with pirfenidone (identifier NCT01417156). ${ }^{47,48}$ 


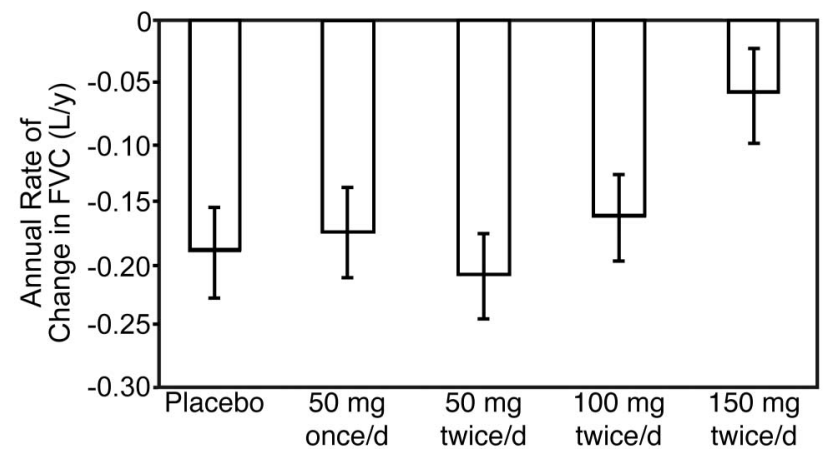

Fig. 1. Annual rate of change in FVC following the administration of nintedanib (TOMORROW trial). Data are expressed as mean \pm SD.

\section{Clinical Trials}

The TOMORROW study was a 12-month, randomized, placebo-controlled, phase- 2 study evaluating the efficacy and safety of 4 nintedanib doses $(50 \mathrm{mg}$ once daily, $50 \mathrm{mg}$ twice daily, $100 \mathrm{mg}$ twice daily, $150 \mathrm{mg}$ twice daily) in subjects with IPF. ${ }^{33}$ Subjects were at least 40 y old with a predefined IPF diagnosis of $<5 \mathrm{y}$ prior to the study screening. Eligible subjects had FVC $\geq 50 \%$, predicted $\mathrm{D}_{\mathrm{LCO}} 30-$ $79 \%$, and $\mathrm{P}_{\mathrm{aO}_{2}} \geq 55 \mathrm{~mm} \mathrm{Hg}$. Concomitant oral therapy with prednisone (or equivalents) at $\leq 15 \mathrm{mg}$ was administered if the patient was stable during the 8 weeks previous to study enrollment. ${ }^{32}$ The primary efficacy end point was represented by the FVC decline rate, and the secondary end points included changes from baseline in FVC, $\mathrm{D}_{\mathrm{LCO}}, \mathrm{S}_{\mathrm{pO}_{2}}$, total lung capacity, exercise capacity, St George Respiratory Questionnaire (SGRQ) scores, incidence of acute exacerbations, and overall mortality. The highest BIBF 1120 dose was associated with the most significant therapeutic effect on the lung function decline compared to placebo, with the drug reducing the annual rate of lung function decline by $68.4 \%$ compared to the placebo group. The highest dose of BIBF 1120 therapy was also associated with a lower percentage of subjects exhibiting a significant reduction of FVC (of $>10 \%$ or $>200 \mathrm{~mL}$ ) compared to the placebo group (23.8 vs $44 \%, P=.004$ ). Unlike the placebo, BIBF 1120 preserved the total lung capacity $(-0.24$ vs $0.12 \mathrm{~L}, P<.004)$ (Fig. 1$)$. Mean change from baseline in $\mathrm{S}_{\mathrm{pO}_{2}}$ was $-0.2 \%$ with BIBF 1120 and $-1.3 \%$ with placebo $(P=.02)$. The highest dose therapy was also associated with a lower percentage of significant desaturation ( $>4 \%$ reduction from baseline in resting $\mathrm{S}_{\mathrm{pO}_{2}}$ ) over the study period (3.6\% for BIBF 1120 and $11.0 \%$ for placebo, $P=.03$ ). BIBF 1120 did not exert a significant therapeutic benefit on $\mathrm{D}_{\mathrm{LCO}}$ and on the exercise capacity compared to placebo. Health-related quality of life evaluated with the SGRQ was found to be significantly improved with the highest BIBF dose compared to placebo. The difference was also clinically important: mean change of -0.66 points with the active treatment compared to 5.46 points with placebo $(P=.007)$. The most significant therapeutic benefit was detected in the SGRQ score: 9.6unit improvement with BIBF 1120 compared to placebo $(P=.003) .{ }^{49}$ The highest BIBF 1120 dose was associated with a significant reduction in the incidence of acute exacerbations compared to placebo (2.4 vs 15.7 per 100 subject years, $P=.02$ ). The $150-$ and $100-\mathrm{mg}$ BIBF 1120 doses were also associated with a trend toward a lower mortality rate compared to placebo $(P=.04$ for $100 \mathrm{mg}$ and $P=.06$ for $150 \mathrm{mg}$ ). No significant differences in terms of mortality rates in the treatment groups compared to placebo were reported. Two phase-3 studies aimed at evaluating the efficacy and safety of BIBF 1120 at $150 \mathrm{mg}$ twice daily for 52 weeks in subjects with IPF are also planned. These 2 studies have similar end points, which include the annual decline rate in FVC, quality of life, time to first exacerbation, and overall survival. ${ }^{50}$

\section{Future Directions}

The results of the TOMORROW study were sufficiently positive for Boehringer Ingelheim (who introduced BIBF 1120 ) to undertake 2 parallel phase- 3 registration studies of nintedanib in IPF (ClinicalTrials.gov identifiers NCT01335464 and NCT01335477). These studies, IMPULSIS I and II, are identical 52-week trials of nintedanib administered at $150 \mathrm{mg}$ twice daily compared to placebo. As with the TOMORROW study, the primary end point is annual rate of decline in FVC (expressed in $\mathrm{mL}$ over 52 weeks). Target recruitment was $\sim 550$ subjects for each study. Both trials were initiated in April 2011, and it is anticipated that the final study visit will be conducted in the first half of 2014. It is to be hoped, therefore, that results will be available later in 2014 .

The TOMORROW study represents an important advance in the treatment of IPF. ${ }^{43,51,52}$ Compared with other treatment approaches, including the administration of antioxidants such as $\mathrm{N}$-acetylcysteine and of pirfenidone, the nonspecific suppression of the inflammatory response with systemic glucocorticoids and potent immunosuppressive agents such as azathioprine and cyclophosphamide, and the use of antifibrotic cytokines such as interferon gamma$1 \mathrm{~b}$, phosphodiesterase-5 inhibitors, and endothelin receptor antagonists, the beneficial effects of BIBF 1120 on the selected population seem to be far better. Newer inhibitors of fibrogenic pathways now being developed may have the potential to produce even more effective treatments that selectively target fibrogenic pathways without affecting the immune and inflammatory responses.

\section{Summary}

IPF is a debilitating, progressive, and possibly fatal disease. Encouraging data suggest that targeting PDGF, VEGF, 
and FGF receptors slows the development of fibrosis. The multiple targeting of these 3 mediators by the novel tyrosine kinase inhibitor nintedanib has led to promising clinical trial results. Preclinical and clinical data demonstrated that high-dose oral nintedanib is able to slow the progression of lung fibrosis and the decline of lung function and reduce the rate of exacerbations in individuals with mild and moderate IPF. Importantly for subjects with this chronic progressive disease, nintedanib improves the quality of life compared with placebo, and it is safe to use. The results of more clinical trials with nintedanib are eagerly awaited to determine the role of nintedanib in the management of IPF.

\section{REFERENCES}

1. Raghu G, Collard HR, Egan JJ, Martinez FJ, Behr J, Brown KK, et al. An official ATS/ERS/JRS/ALAT statement: idiopathic pulmonary fibrosis: evidence-based guidelines for diagnosis and management. Am J Respir Crit Care Med 2011;183(6):788-824.

2. King TE Jr., Pardo A, Selman M. Idiopathic pulmonary fibrosis. Lancet 2011;378(9807):1949-1961.

3. Walter N, Collard HR, King TE Jr. Current perspectives on the treatment of idiopathic pulmonary fibrosis. Proc Am Thorac Society 2006;3(4):330-338.

4. Sode BF, Dahl M, Nielsen SF, Nordestgaard BG. Venous thromboembolism and risk of idiopathic interstitial pneumonia: a nationwide study. Am J Respir Crit Care Med 2010;181(10):1085-1092.

5. Douglas WW, Ryu JH, Schroeder DR. Idiopathic pulmonary fibrosis: impact of oxygen and colchicine, prednisone, or no therapy on survival. Am J Respir Crit Care Med 2000;161(4 Pt 1):1172-1178.

6. Collard HR, Ryu JH, Douglas WW, Schwarz MI, Curran-Everett D, King TE Jr., Brown KK. Combined corticosteroid and cyclophosphamide therapy does not alter survival in idiopathic pulmonary fibrosis. Chest 2004;125(6):2169-2174.

7. King TE Jr., Brown KK, Raghu G, du Bois RM, Lynch DA, Martinez F, et al. BUILD-3: a randomized, controlled trial of bosentan in idiopathic pulmonary fibrosis. Am J Respir Crit Care Med 2011; 184(1):92-99.

8. King TE Jr., Albera C, Bradford WZ, Costabel U, Hormel P, Lancaster $\mathrm{L}$, et al. Effect of interferon gamma-1b on survival in patients with idiopathic pulmonary fibrosis (INSPIRE): a multicentre, randomised, placebo-controlled trial. Lancet 2009;374(9685):222-228.

9. Lower EE, Baughman RP. The use of low dose methotrexate in refractory sarcoidosis. Am J Med Sci 1990;299(3):153-157.

10. Venuta F, Rendina EA, Ciriaco P, De Giacomo T, Pompeo E, Bachetoni A, Ricci C. Efficacy of cyclosporine to reduce steroids in patients with idiopathic pulmonary fibrosis before lung transplantation. J Heart Lung Transplant 1993;12(6 Pt 1):909-914.

11. Selman M, Carrillo G, Salas J, Padilla RP, Pérez-Chavira R, Sansores R, Chapela R. Colchicine, D-penicillamine, and prednisone in the treatment of idiopathic pulmonary fibrosis: a controlled clinical trial. Chest 1998;114(2):507-512.

12. Daniels CE, Lasky JA, Limper AH, Mieras K, Gabor E, Schroeder DR, Imatinib-IPF Study Investigators. Imatinib treatment for idiopathic pulmonary fibrosis: randomized placebo-controlled trial results. Am J Respir Crit Care Med 2010;181(6):604-610.

13. Raghu G, Brown KK, Costabel U, Cottin V, du Bois RM, Lasky JA, et al. Treatment of idiopathic pulmonary fibrosis with etanercept: an exploratory, placebo-controlled trial. Am J Respir Crit Care Med 2008;178(9):948-955.
14. Behr J, Degenkolb B, Krombach F, Vogelmeier C. Intracellular glutathione and bronchoalveolar cells in fibrosing alveolitis: effects of N-acetylcysteine. Eur Respir J 2002;19(5):906-911.

15. Davies HR, Richeldi L, Walters EH. Immunomodulatory agents for idiopathic pulmonary fibrosis. Cochrane Database Syst Rev 2003; (3):CD003134.

16. Luppi F, Cerri S, Beghè B, Fabbri LM, Richeldi L. Corticosteroid and immunomodulatory agents in idiopathic pulmonary fibrosis. Respir Med 2004;98(11):1035-1044.

17. Datta A, Scotton CJ, Chambers RC. Novel therapeutic approaches for pulmonary fibrosis. Br J Pharmacol 2011;163(1):141-172.

18. Droogendijk HJ, Kluin-Nelemans HJ, van Doormaal JJ, Oranje AP, van de Loosdrecht AA, van Daele PL. Imatinib mesylate in the treatment of systemic mastocytosis: a phase II trial. Cancer 2006; 107(2):345-351.

19. Fausel C. Targeted chronic myeloid leukemia therapy: seeking a cure. Am J Health Syst Pharm 2007;64(24 Suppl 15):S9-S15.

20. Goldman JM, Melo JV. Targeting the BCR-ABL tyrosine kinase in chronic myeloid leukemia. N Engl J Med 2001;344(14):1084-1086.

21. Stegmeier F, Warmuth M, Sellers WR, Dorsch M. Targeted cancer therapies in the twenty-first century: lessons from imatinib. Clin Pharmacol Ther 2010;87(5):543-552.

22. Maher TM. Pirfenidone in idiopathic pulmonary fibrosis. Drugs Today 2010;46(7):473-482.

23. Spagnolo P, Del Giovane C, Luppi F, Cerri S, Balduzzi S, Walters $\mathrm{EH}$, et al. Non-steroid agents for idiopathic pulmonary fibrosis. Cochrane Database Syst Rev 2010;(9):CD003134.

24. Bouros D. Pirfenidone for idiopathic pulmonary fibrosis. Lancet 2011; 377(9779):1727-1729.

25. Taniguchi H, Ebina M, Kondoh Y, Ogura T, Azuma A, Suga M, et al. Pirfenidone in idiopathic pulmonary fibrosis. Eur Respir J 2010; 35(4):821-829.

26. Roth GJ, Heckel A, Colbatzky F, Handschuh S, Kley J, LehmannLintz T, et al. Design, synthesis, and evaluation of indolinones as triple angiokinase inhibitors and the discovery of a highly specific 6-methoxycarbonyl-substituted indolinone (BIBF 1120). J Med Chem 2009;52(14):4466-4480.

27. Hilberg F, Roth GJ, Krssak M, Kautschitsch S, Sommergruber W, Tontsch-Grunt U, et al. BIBF 1120: triple angiokinase inhibitor with sustained receptor blockade and good antitumor efficacy. Cancer Res 2008;68(12):4774-4782.

28. Chaudhary NI, Roth GJ, Hilberg F, Müller-Quernheim J, Prasse A, Zissel G, et al. Inhibition of PDGF, VEGF and FGF signalling attenuates fibrosis. Eur Respir J 2007;29(5):976-985.

29. Keane MP, Arenberg DA, Lynch JP 3rd, Whyte RI, Iannettoni MD, Burdick MD, et al. The CXC chemokines, IL-8 and IP-10, regulate angiogenic activity in idiopathic pulmonary fibrosis. J Immunol 1997; 159(3): 1437-1443.

30. Nissen LJ, Cao R, Hedlund EM, Wang Z, Zhao X, Wetterskog D, et al. Angiogenic factors FGF2 and PDGF-BB synergistically promote murine tumor neovascularization and metastasis. J Clin Invest 2007; 117(10):2766-2777.

31. Hamada N, Kuwano K, Yamada M, Hagimoto N, Hiasa K, Egashira $\mathrm{K}$, et al. Anti-vascular endothelial growth factor gene therapy attenuates lung injury and fibrosis in mice. J Immunol 2005;175(2):12241231.

32. Richeldi L, Costabel U, Selman M, Kim DS, Hansell DM, Nicholson AG, et al. Efficacy of a tyrosine kinase inhibitor in idiopathic pulmonary fibrosis. N Engl J Med 2011;365(12):1079-1087.

33. Günther A, Korfei M, Mahavadi P, von der Beck D, Ruppert C, Markart P. Unravelling the progressive pathophysiology of idiopathic pulmonary fibrosis. Eur Respir Rev 2012;21(124):152-160.

34. Gotink KJ, Verheul HM. Anti-angiogenic tyrosine kinase inhibitors: what is their mechanism of action? Angiogenesis 2010;13(1):1-14. 


\section{Nintedanib IN IDIOPATHIC PUlmonary Fibrosis}

35. Inoue Y, King TE Jr., Barker E, Daniloff E, Newman LS. Basic fibroblast growth factor and its receptors in idiopathic pulmonary fibrosis and lymphangioleiomyomatosis. Am J Respir Crit Care Med 2002;166(5):765-773.

36. Lo Re S, Lecocq M, Uwambayinema F, Yakoub Y, Delos M, Demoulin $\mathrm{JB}$, et al. Platelet-derived growth factor-producing $\mathrm{CD} 4^{+}$ $\mathrm{Foxp}^{+}$regulatory $\mathrm{T}$ lymphocytes promote lung fibrosis. Am J Respir Crit Care Med 2011;184(11):1270-1281.

37. Ebina M, Shimizukawa M, Shibata N, Kimura Y, Suzuki T, Endo M, et al. Heterogeneous increase in CD34-positive alveolar capillaries in idiopathic pulmonary fibrosis. Am J Respir Crit Care Med 2004; 169(11):1203-1208

38. Renzoni EA. Neovascularization in idiopathic pulmonary fibrosis: too much or too little? Am J Respir Crit Care Med 2004;169(11): 1179-1180.

39. Simler NR, Brenchley PE, Horrocks AW, Greaves SM, Hasleton PS, Egan JJ. Angiogenic cytokines in patients with idiopathic interstitial pneumonia. Thorax 2004;59(7):581-585.

40. Cosgrove GP, Brown KK, Schiemann WP, Serls AE, Parr JE, Geraci MW, et al. Pigment epithelium-derived factor in idiopathic pulmonary fibrosis: a role in aberrant angiogenesis. Am J Respir Crit Care Med 2004;170(3):242-251

41. Koyama S, Sato E, Haniuda M, Numanami H, Nagai S, Izumi T, Decreased level of vascular endothelial growth factor in bronchoalveolar lavage fluid of normal smokers and patients with pulmonary fibrosis. Am J Respir Crit Care Med 2002;166(3):382-385.

42. Meyer KC, Cardoni A, Xiang ZZ. Vascular endothelial growth factor in bronchoalveolar lavage from normal subjects and patients with diffuse parenchymal lung disease. J Lab Clin Med 2000;135(4):332338.

43. Woodcock HV, Molyneaux PL, Maher TM. Reducing lung function decline in patients with idiopathic pulmonary fibrosis: potential of nintedanib. Drug Des Devel Ther 2013;7:503-510.

44. Stopfer P, Rathgen K, Bischoff D, Lüdtke S, Marzin K, Kaiser R, et al. Pharmacokinetics and metabolism of BIBF 1120 after oral dosing to healthy male volunteers. Xenobiotica 2011;41(4):297-311.

45. Gori B, Ricciardi S, Fulvi A, Del Signore E, de Marinis F. New oral multitargeted antiangiogenics in non-small-cell lung cancer treatment. Future Oncol 2012;8(5):559-573.

46. Gori B, Ricciardi S, Fulvi A, Intagliata S, Del Signore E, de Marinis F. New antiangiogenics in non-small cell lung cancer treatment: Vargatef (BIBF 1120) and beyond. Ther Clin Risk Manag 2011;7:429-440.

47. Lota HK, Wells AU. The evolving pharmacotherapy of pulmonary fibrosis. Expert Opin Pharmacother 2013;14(1):79-89.

48. Cottin V. Interstitial lung disease. Eur Respir Rev 2013;22(127):2632.

49. Brown KK, Richeldi L, Costabel U, Flaherty KR, Kim D, Noble PW, et al. Treatment of IPF with the tyrosine kinase inhibitor BIBF 1120: patient-reported outcomes in the TOMORROW trial. Am J Respir Crit Care Med 2012;185(A3634).

50. Safety and efficacy of BIBF 1120 at high dose in idiopathic pulmonary fibrosis patients. March 25, 2014. Identifier NCT01335464. http://clinicaltrials.gov.

51. Antoniu SA. Nintedanib (BIBF 1120) for IPF: a tomorrow therapy? Multidiscip Respir Med 2012;7(1):41.

52. Downey GP. Resolving the scar of pulmonary fibrosis. N Engl J Med 2011;365(12):1140-1141. 